\title{
CIERPLIWOŚĆ FANA FANTASTYKI O TYM, CZY FAN TO MARIONETKA CZY PARTYZANT
}

W języku potocznym „fan” to określenie bardzo nieostre. Często używa się go, aby opisać wielbicieli celebrities lub grupę szalikowców kibicujących jakiejś piłkarskiej drużynie. Mało tego - można być fanem lodów czekoladowych, kotów bądź psów, kuchni śródziemnomorskiej, a nawet jakiegoś regionu turystycznego. Pojęcia „fan” używa się zatem w dość dowolny sposób, opisując wiele zjawisk, często niewspółmiernych oraz znacznie się różniących. To z pewnością błąd. Przed podjęciem rozważań dotyczących fanów warto jasno określić, kim oni są. Nie można ich postrzegać według potocznych wyobrażeń i stereotypów. Dalsze rozważania dotyczyć będą nie wielbicieli dowolnej rzeczy, lecz zwolenników produktów ze sfery kultury popularnej. Fani różnią się od innych odbiorców owej kultury - to publiczność różnorodnych tekstów, specyficzna ze względu na kilka cech.

Przede wszystkim fani są niezwykle zaangażowani w odbiór - obcują z danym produktem medialnym bardzo często (por. Godzic 2001, s. 183-185). W tym względzie można ich uznać za konsumentów wzorowych (por. Kitabayashi 2004, s. 4). Jako tacy są niezwykle kompetentnymi odbiorcami. Mogą pochwalić się ogromną wiedzą na temat przedmiotu uwielbienia, w tym najmniejszych detali z nim się wiążących, a także intensyfikują swoją przyjemność w związku z czymś, co można nazwać wtórną produkcją. Nie ograniczają się do konsumpcji, są również twórcami tekstów opartych na oryginale (por. Siuda 2008a).

Można mówić w tym kontekście o produkcji różnorodnych amatorskich grafik, obrazów, filmów, utworów muzycznych, opowiadań literackich (Pugh 2005; Jenkins 1988; Mittell 2009; Stein 2010). Wymianę takich tekstów znacz-

Adres do korespondencji: piotr.siuda@gmail.com 
nie ułatwia elektroniczna sieć internetowa, która przyczynia się do popularyzacji społeczności fanowskich. Warto podkreślić, że fani nie są samotnikami, nie izolują się od innych, nie ukrywają swojej pasji przed otoczeniem, nie tworzą tylko i wyłącznie dla siebie. Są prospołeczni, chcą i dążą do tego, żeby organizować się w społeczności oparte na mniej lub bardziej trwałych więziach. Egzemplifikacją tego jest wykwit różnego rodzaju wspólnot wirtualnych, czyli tych powstających $\mathrm{w}$ internecie. Fora, czaty, serwisy WWW - każdy z fanów znajdzie sposób, aby nawiązać kontakt $\mathrm{z}$ innym pokrewnym osobnikiem (Bury 2005; Kirby-Diaz 2009; Ali 2009). Internet popularyzuje i rozwija społeczności fanowskie, działalność sieciowa niejednokrotnie inicjuje realny kontakt (Siuda 2008b, s. 239-256).

Kiedy rozważa się, jakiego rodzaju teksty mają zdecydowanie najwięcej miłośników, należy wskazać produkty audiowizualne (filmy, seriale). Oczywiście nie jest tak, że fan odrzuci produkcje innego typu, jeśli wiązać się one będą w jakiś sposób $z$ tym, co znane jest $z$ ekranów telewizorów bądź sal kinowych. Tego rodzaju produkcji powstaje zresztą bardzo dużo - współczesna popkultura podlega procesom synergii - wokół tego, co zyskuje popularność, tworzy się automatycznie całą gamę innego rodzaju tekstów. Na podstawie popularnego filmu czy serialu mogą powstać gry, książki, komiksy, różnego rodzaju gadżety ${ }^{1}$. Jednak fan jest przede wszystkim wielbicielem produkcji źródłowej - to ona jest kanonem, czymś, co służy ocenianiu wszystkich produkcji pobocznych (por. Siuda 2010).

Poniższe rozważania dotyczą miłośników audiowizualnych tekstów z gatunku science-fiction i fantasy. To właśnie fani fantastyki stanowią awangardę społeczności fanowskich. Pierwsze takie społeczności formowały się wokół tekstów fantastycznych, w szczególności emitowanego w Stanach Zjednoczonych w latach sześćdziesiątych serialu Star Trek (Coppa 2006, s. 41-59)². Współcześnie bardzo często można spotkać wielbicieli innych tekstów sci-fi bądź fantasy. Dużo jest tych, którzy fascynują się filmem Star Wars. Równie często można spotkać fanów identyfikujących się z załogą statku kosmicznego USS Enterprise (chodzi o nowsze serie z cyklu Star Trek) czy z bohaterami trylogii Tolkiena.

${ }^{1}$ Henry Jenkins ukuł dla tego rodzaju zabiegów specyficzne pojęcie. Mówi on o opowiadaniach transmedialnych - produktach, które zaistniały na rozmaitych platformach medialnych. Jako przykład podaje film Matrix - ponieważ cieszył się on ogromnym zainteresowaniem, producenci postanowili zrealizować na jego podstawie grę oraz wydać książki i komiksy. Co ważne, każdy z tych produktów jest istotny dla doświadczania filmu przez fana, każdy bowiem wnosi inne elementy pozwalające zrozumieć mechanizmy rządzące fikcyjnym światem, jaki ukazuje Matrix (Jenkins 2007b, s. 117-128).

2 Bardzo często dowodzi się, że zjawisko fanizmu zaistniało nawet wcześniej, w latach trzydziestych. W Stanach Zjednoczonych Ameryki zawiązywać zaczęły się wówczas fankluby miłośników fantastyki naukowej. Powstały one wokół czasopism publikujących opowiadania fantastyczne. Na ich łamach redaktorzy pozwalali czytelnikom korespondować ze sobą, co spowodowało powstanie specyficznych społeczności. Kluczowy dla nich okazał się rok 1932, wówczas został zorganizowany pierwszy zjazd fanów fantastyki - Światowy Konwent Science Fiction. 
Wielbicieli różnego rodzaju audiowizualnych tekstów z kręgu fantastyki jest bardzo dużo, są oni najaktywniejsi, tworzą największe społeczności. Angielskojęzyczna literatura dość dobrze udokumentowała to zjawisko - istnieje wiele etnograficznych opisów wspólnot fanów fantastyki, poświęconych miłośnikom rozmaitych zjawisk popkulturowych (Bacon-Smith 2000; Brooker 2002).

\section{FAN FANTASTYKI — MANIPULOWANA MARIONETKA}

Audiowizualna fantastyka często uważana jest za kiczowatą. Oczywiście bardzo trudno jest zdefiniować kicz oraz w sposób jasny wskazać, co nim jest, a co nie. Wielu teoretyków ma na ten temat bardzo różne pomysły. Kicz często porównuje się do sztuki, przy czym jest on tym wszystkim, czym ona nie jest. $\mathrm{Z}$ tej perspektywy traktowany jest negatywnie, pogardliwie i deprecjonująco. Jest gorszy, mniej wartościowy, niewart uwagi oraz nieskłaniający do żadnej głębszej refleksji. Oczywiście takie rozumienie kiczu rodzi pewien problem, na który wskazuje chociażby Marina Noske (jej niepublikowany artykuł przytoczyła w swojej pracy Agata Bisko; 2008, s. 102). Noske twierdzi, że definicje kiczu tworzone tylko i wyłącznie przez przeciwstawienie sztuce są błędne, ponieważ trudno o spójną definicję tej ostatniej. $Z$ tego powodu przeciwstawiając kicz sztuce, teoretycy wskazują zwykle jakieś jego cechy. Abraham Moles (1978, s. 76-80) mówi o kumulacji elementów składających się na dzieło, ich wzajemnym niedostosowaniu, przeciętności, komforcie, który odczuwa odbiorca. Wspomniana wyżej Noske uważa, że kicz jest: „pozbawiony oryginalności, naśladowczy, konwencjonalny, powierzchowny; swą atrakcyjność zawdzięcza cechom najprymitywniejszym; jest nierzetelny, robiony nie na serio, pretensjonalny, tani; znamionuje go łatwa dostępność formy i czytelność treści znanej wszystkim" (zob. Bisko 2008, s. 102).

Za takiego rodzaju kicz uważa się właśnie audiowizualną fantastykę, jej odbiorców traktując jako publiczność gorszego rodzaju. Ciekawie pisze o tym Teresa Ebert (1980, s. 92), która uważa, że audiowizualne produkcje fantastyczne opierają się na schemacie „zastrzel, jak się poruszy”. Chodzi o koncentrowanie się na akcji, efektach specjalnych oraz widowiskowości. Teksty tego rodzaju są prymitywne i banalne, rzec można, gadżeciarskie. Autorka przeciwstawia je fantastyce poważnej, filozofującej, nastawionej na pokazywanie alternatywnych systemów społecznych czy skłaniającej do refleksji na temat kondycji współczesnego świata lub natury człowieka. Według Ebert, można wyróżnić różne nurty współczesnej fantastyki. Pierwszy nazywa ona metafantastyką i utożsamia z poważną literaturą, która opiera się na samorefleksyjności, polegającej na świadomości własnego statusu estetycznego oraz świadomości sztuczności świata przedstawionego tekstów. Fantastyka literacka nie stara się udawać, że wizje, które przedstawia, są realistyczne, przeciwnie - uświadamia, że są one artefaktem, tworem stworzonym, aby służyć jakimś celom. W tym wypadku chodzi o odnoszenie się do niebanalnych problemów natury socjologicznej czy 
psychologicznej. Fantastyka literacka w pewnym sensie jest również realna stara się operować w granicach prawdopodobieństwa, to znaczy tworzyć spójny obraz świata. Jest mniej efektowna niż audiowizualna, nie jest gadżeciarska, a przez to trywialna. Drugi nurt autorka utożsamia z owymi banalnymi tekstami audiowizualnymi. Nazywa je parafantastyką, w której próżno jest szukać filozofii, socjologii, psychologii, nie ma w niej również miejsca na głębsze przemyślenia o otaczającym świecie.

Poglądy Teresy Ebert podziela wielu innych teoretyków, na czele z Lesterem del Rey (1979, s. 304-315) czy Brianem Aldissem (1986, s. 271-284), którzy w audiowizualnej fantastyce widzą infantylną wersję literatury poważnej. Bardzo często podkreśla się, że fantastyka literacka, podobnie jak sztuka, cieszy się uznaniem. Jest obiektem akademickich rozważań, naukowych dociekań, wielu interpretacji. Teksty z jej obrębu stają się obiektami ważnymi, osiągają status wartościowych i prestiżowych. Według Adriana Mellora (1984, s. 39-40), dzieje się tak, ponieważ przedstawiają pesymistyczne spojrzenie na świat. Skupiają się na krytyce kapitalizmu, ukazują dystopijne wizje świata, krytykują mroczne oblicze natury ludzkiej. Mellor nawiązuje do koncepcji wyróżnianych przez Pierre'a Bourdieu klas społecznych. Pierwsza, w skład której wchodzą kapitaliści, przedsiębiorcy, menedżerowie, skoncentrowana jest na produkcji, podtrzymuje siebie poprzez kapitał materialny. Druga operuje kapitałem kulturowym, dysponuje nie tyle pieniądzem, ile siłą symboliczną. Klasa ta tworzy kulturę, w jej skład wchodzą artyści, naukowcy, inteligencja. Obie grupy są do siebie nastawione wrogo - można mówić o rywalizacji kapitału materialnego z kapitałem symbolicznym. Mellor pokazuje, że przeciwstawiając się klasie przedsiębiorców, grupa operująca kapitałem symbolicznym wynosi na piedestał teksty zawierające krytykę kapitalizmu, w tym dystopijną, mroczną, pesymistyczną metafantastykę. Jeśli przez pryzmat poglądów Mellora spojrzymy na parafantastykę, to wyjaśnia się, dlaczego pozostaje ona na uboczu, dlaczego jest odtrącona przez klasę inteligencji, uważana za nic nie wartą. Jest odrzucana jako lansująca optymistyczne, afirmatywne podejście do współczesnego, rządzonego przez pieniądz świata.

Ukazywanie audiowizualnej fantastyki jako twórczości kiczowatej ma szczególne znaczenie, gdy analizuje się jej miłośników. Jak łatwo zauważyć, negatywne waloryzowanie gatunku to element nieprzychylnego podejścia do fanów, pokazywania ich jako odbiorców patologicznych. Podkreślanie uwielbienia bezwartościowych tekstów (świadczącego o dewiacyjności) jest częścią specyficznej postawy badawczej. Określić ją można jako podejście patologiczne, ukazujące fana jako, rzec można, infantylną marionetkę. Fan staje się nią wskutek zachłyśnięcia się kiczowatością wielbionego tekstu. Kiczowatość czyni z audiowizualnej fantastyki towar łatwostrawny i przez to tak bardzo popularny. Chodzi tu o sytuację całkowitego bezguścia, poddania się kiczowatemu, zestandaryzowanemu produktowi. Takie ubezwłasnowolnienie skutkuje ogłupieniem oraz uleganiem manipulatorskim zapędom producentów. Kiczowatość tekstów 
czyni je odpowiednimi dla mas fanów niezdolnych do namysłu i zadumy nad rzeczywistymi ich celami.

Podejście patologiczne wyraźnie nawiązuje do szkoły frankfurckiej, której twórcy zakładali bezwolność odbiorców kultury popularnej. Theodor Adorno, Max Horkheimer czy Herbert Marcuse podkreślali, że odbiorcy są manipulowani przez przemysł kulturowy, który chce utrzymać istniejące nierówności społeczne. Czyni to przez nakłanianie do konsumpcji, która wzbudza tak zwane fałszywe potrzeby (Marcuse 1991, s. 13-27). Implikują one bezmózgie pochłanianie papki, którą serwują mass media. Kultura popularna przez frankfurtczyków była postrzegana jako narzędzie w rękach elity, mające służyć przypodobaniu się ludziom, perswazji, manipulowaniu nimi i eksploatowaniu ich, tak aby stawali się niewolnikami komercyjnego kapitalizmu oraz demokratycznego ustroju państwowego (por. Strinati 2005, s. 15-49). Na gruncie takich koncepcji odbiorcy to zdziecinniałe marionetki, którym podoba się brak intelektualnych wyzwań i stymulacji. Preferują oni wygodę fantazji oraz eskapizmu, sprzeczną z wysiłkiem myślenia. Podobne poglądy wyrażał Dwight MacDonald (2002). Zatomizowanie masowej publiczności skutkuje, według niego, obniżeniem poziomu kultury w ogóle oraz zagraża kulturze elitarnej. Twierdził tak również Richard Hoggart - angielski badacz, który podjął to zagadnienie w dziele Spojrzenie na kulturę robotnicza w Anglii (1976). Upadek spowodowany wpływami kultury popularnej pokazał on na przykładzie młodzieży $z$ angielskiej klasy robotniczej, która ulega amerykańskiemu barbarzyństwu (jak nazywał popkulturę), co staje się przyczyną utraty tradycyjnych korzeni.

Poglądy przedstawicieli podejścia patologicznego osadzić można ponadto w ogólniejszej krytyce fanów. Zdaniem Joli Jenson (1992, s. 10-16) owo negatywne spojrzenie na fanów jest mocno powiązane $z$ występującą $w$ środowisku akademickim krytyką nowoczesności, w której upatruje się przyczyny atomizacji, alienacji, rozproszenia więzi społecznych, uformowania fragmentarycznej, niekompletnej jaźni. John Storey (2003, s. 117) wywody autorki podsumował następująco: „W oczach naukowców ruch fanów stanowi wyraźny (patologiczny) objaw rzekomej kulturowej, moralnej i społecznej niemocy, która jest bez wątpienia następstwem przekształcenia społeczeństwa wiejskiego i rolniczego w społeczeństwo przemysłowe i miejskie". Dla akademików fani są ucieleśnieniem tego wszystkiego, czego należy się bać $\mathrm{w}$ związku z nowoczesnością. Poza tym można powiedzieć, że krytyka ta podparta jest chęcią wzmocnienia samooceny. Wielbiciele zachowują się przecież w sposób, który wymaga potępienia - są sentymentalni, banalni, dziecinni. Stanowią oni dla badaczy grupę „obcą”, która przeciwstawna jest grupie „naszej” — poważnych, patrzących z rozwagą i trzeźwością, zdystansowanych do otaczającego świata uczonych ${ }^{3}$.

3 Przykładów tego rodzaju krytyki znaleźć można bardzo wiele. Jednym z ciekawszych jest propozycja Stephena Hinermana (1992), który uważa, że zdziecinnienie fanów najwyraźniej przejawia 
Jak zostało powiedziane, według reprezentantów podejścia patologicznego fani kiczowatych fantastycznych serii i filmów są manipulowaną, bezwolną masą - są infantylnymi marionetkami w teatrze producentów. Bernard Sharratt (1980, s. 284-286) uważa, że wiedza miłośników fantastyki na temat ich ulubionych tekstów jest niewiele warta. Przede wszystkim dlatego że zastępuje wiedzę o świecie rzeczywistym, w szczególności o społecznych i ekonomicznych jego strukturach jako narzędziach manipulacji i wyzysku. Ktoś poddany wpływom fantastycznych produkcji, które oferują pseudonaukowe teorie czy przedstawiają fikcyjne światy, może czuć się uspokojony czy wręcz zadowolony. Ma bowiem wrażenie wglądu w mechanizmy funkcjonowania współczesnego świata - wrażenie to jest oczywiście złudne, gdyż zamiast uzyskania wiedzy fan poddany jest manipulacji.

Jeszcze dalej w krytyce fanów fantastyki idzie Jay Goulding w książce Empire, Aliens and Conquest (1985). Egzemplifikacją tego, jak oddziałują na nich audiowizualne przekazy fantastyczne, są dlań Star Trek oraz Star Wars. Według Gouldinga, kultowe filmy fantastyczne stają się częścią systemu społecznego opartego na sprzecznościach. Systemu, który głosi wolność, lecz stosuje dominację i opresję, sytemu, który promuje pokój, lecz uczestniczy w wojnie, systemu, który stawia na wolność ekonomiczną, lecz wspiera interesy wielkich korporacyjnych monopoli. Fantastyka wspiera ów system (przemysł kulturowy dokonuje swoistego prania mózgów).

Bezpośrednio nawiązując do teorii Adorna, Goulding twierdzi, że zarówno Star Trek jak i Star Wars na powierzchni wydają się inne. W rzeczywistości jednak promują pseudoindywidualizm opierający się na standaryzacji. Obydwa teksty przedstawiają bohaterów, których wybory oparte są na ścisłych regułach oraz strukturalnych nierównościach. Na przykład Kirk (kapitan ze Star Treka) to awanturnik działający zgodnie z Dyrektywami Federacji (przyszły ustrój w serialu). Zasady te, według Gouldinga, opierają się na męskiej dominacji, seksizmie (większość oficerów to mężczyźni), promują kapitalizm (kolonizowanie i obrona rozmaitych planet) oraz darwinowską etykę - przetrwa ten, kto jest silniejszy. Aby potwierdzić swoją tezę, Goulding analizuje wiele odcinków serialu, szczególnie te, w których głównodowodzący okrętu USS Enterprise narusza tak zwaną Pierwszą Dyrektywę, mówiącą o nieingerowaniu w kultury innych światów. Wielokrotne jej łamanie, mające na celu zaprowadzenie federacyjnego porządku na odwiedzanych planetach, nie jest, jego zdaniem, niczym innym jak tylko usprawiedliwieniem ekspansji światowego kapitalizmu oraz polityki prowadzonej przez rząd Stanów Zjednoczonych. Obiektem agresji załogi okrętu kosmicznego są społeczeństwa inne niż demokratyczne - komunistyczne, socjalistyczne, kobiece. Za przyjazną twarzą Federacji, za 
jej prawami oraz stawianiem na wolny rozwój, kryje się twarz druga - dominacji oraz podporządkowywania sobie innych, kulturowej supremacji, która każe Kirkowi oraz jego załodze uczyć obcych, jak podążać jedyną właściwą, kapitalistyczną drogą. Niezwykle zaangażowani w odbiór fani utożsamiają się $z$ bohaterami i ich ideami, takimi jak: promowanie kapitalizmu, konkurencja, konieczność ulegania władzy.

Audiowizualne teksty fantastyki są zatem częścią systemu, który usprawiedliwia i racjonalizuje nierówności społeczne oraz sprzeczności współczesnych społeczeństw, a także pomaga utrzymać prymat klas rządzących. Produkcje fantastyczne uniemożliwiają bunt, ich odbiorcy poddawani są bowiem specyficznej kontroli społecznej - fani są na nią szczególnie podatni, a przez to stają się manipulowani i bezwolni. Fasadą są oferowane przez Star Trek czy Star Wars wolność i równość - nigdy ich nie uświadczymy. Poza tym teksty owe są niczym mity, ponieważ opierają się na nieustannych powtórzeniach. Jak zatem widać, Goulding przedstawił niezbyt korzystny obraz fanów - są to zaślepieni przez konsumpcję odbiorcy, a ich jedynym celem jest bezmózgie wyczekiwanie na kolejny film czy serial. Taki konsumeryzm wyklucza wszelki opór, uciska i oślepia, eliminuje wszelką zadumę nad otaczającym światem.

\section{FAN FANTASTYKI — OPIERAJĄCY SIĘ PARTYZANT}

Czy rzeczywiście jednak gadżeciarskie, kiczowate i przez to łatwo przyswajalne teksty audiowizualne $\mathrm{z}$ gatunku fantastyki tak bardzo manipulują fanami? Wielu teoretyków ma na ten temat odmienne zdanie. Reprezentują oni postawę badawczą, którą można określić mianem podejścia wojennego. Całkowicie różni się ono od spojrzenia patologicznego, jego zwolennicy przedstawiają bowiem fana jako kogoś „walczącego" z producentami, stawiającego im opór i, co ważniejsze, zdolnego im się przeciwstawić. Pokazują fanów nie jako manipulowany, patologiczny segment odbiorców, ale jako aktywnych i twórczych, a w konsekwencji opierających się wielbicieli. Twierdzą ponadto, że kicz nie oddziałuje tak zniewalająco. Istnieje i fani reagują na niego, ale można powiedzieć, że ich „cierpliwość” ma w tym względzie granice.

Przedstawiciele podejścia wojennego czerpią inspirację z zupełnie innych źródeł. Sięgają na przykład do poglądów Dicka Hebdige’a (1988), który akcentował aktywność odbiorców kultury popularnej, a zaprzeczał bezrefleksyjności i bierności ${ }^{4}$. Ien Ang (1989) twierdziła podobnie - analizując publiczność

${ }^{4}$ Dick Hebdige analizował angielską młodzież pochodzenia robotniczego - czynił to jednak zupełnie inaczej niż Richard Hoggart. Według Hebdige’a młodzież wcale nie konsumuje w sposób bierny i bezrefleksyjny, lecz w sposób aktywny. Korzysta $z$ dostępnych popularnych tekstów kulturowych, sięga po style życia, wyobrażenia, stroje i muzykę, odwołując się do własnych wyobrażeń oraz własnych doświadczeń życiowych. Robotnicy używają amerykańskiej popkultury, aby opierać się (wprawdzie niezbyt radykalnie) kulturze klasy średniej i wyższej — używają jej po prostu jako duchowej obrony przeciwko własnemu podporządkowaniu. 
amerykańskich oper mydlanych (przede wszystkim serialu Dallas), pokazywała, że otwarta jest ona na różnorodne interpretacje. Podejście dialogowe, reprezentowane chociażby przez Martina Barkera, sytuowało odbiorców gdzieś pośrodku — jako poddanych władzy przemysłu kulturowego, ale jednocześnie wywierających nań pewien wpływ (por. Strinati 2005, s. 200-203). Pasywność konsumentów kultury popularnej negowali również przedstawiciele Centre for Contemporary Cultural Studies, działającego przy Uniwersytecie w Birmingham - na przykład David Morley czy Stuart Hall, który sformułował koncepcję przeciwstawnego dekodowania (zob. Szkudlarek 2001, s. 182-191).

Dla przedstawicieli podejścia wojennego duże znaczenie mają również ogólne rozważania na temat fanów utrzymane w duchu zaprzeczania pasywności. Dobrym przykładem są poglądy Johna Fiske. Wykładnię jego koncepcji można znaleźć w dwóch książkach opublikowanych po raz pierwszy w roku 1989 - Reading the Popular (2003) oraz Understanding Popular Culture (2005). Uznaje on polisemiczność tekstów tworzonych w ramach popkultury — innymi słowy, opiera się na założeniu, że niosą one ze sobą ogromną różnorodność znaczeń (Fiske 2005). Pozwala to wielbicielom na dokonywanie alternatywnych odczytań oraz różnorodne interpretowanie ${ }^{5}$. $Z$ tej perspektywy okazuje się, że fani prowadzą specyficzną działalność wywrotową. Na przykładzie Madonny Fiske pokazuje, jak produkt kulturowy staje się niezwykle znaczącym dobrem, które wykorzystuje się w życiu codziennym. Twierdzi, że nastoletnie wielbicielki piosenkarki używają jej jako zasobu symbolicznego, który pozwala obejść patriarchalne konceptualizacje płci kulturowej dominujące we współczesnych społeczeństwach Zachodu. Polisemiczna natura Madonny jako tekstu popkulturowego jest dla wspomnianych dziewcząt niezwykle ważna - stawia znak zapytania nad słusznością tradycyjnego postrzegania kobiet.

Również w odniesieniu do fanów filmów oraz seriali fantastycznych twierdzi się, że nie są oni potulnymi owieczkami prowadzonymi na smyczy producenckiego ucisku. Przedstawiciele podejścia wojennego starają się tego dowieść przez etnograficzne opisy społeczności fanów, organizujących zloty czy produkujących amatorskie teksty oparte na oryginale. Fani stają się, w ich mniemaniu, partyzantami prowadzącymi „podjazdową wojnę” z przemysłem kulturowym, nie są $\mathrm{w}$ związku $\mathrm{z}$ tym podatni na manipulatorskie zapędy.

5 John Fiske (2003) porównuje polisemiczność tekstów kultury popularnej i negocjowanie znaczeń przez fanów do tego, w jaki sposób ludzie używają jednej z części garderoby - jeansów. Badacz pokazuje, że chociaż są one produktem niezwykle rozpowszechnionym, przedstawiciele różnych grup społecznych wykorzystują je w rozmaitych sytuacjach w bardzo różny sposób. Tego rodzaju zróżnicowane użycie jest ilustracją tego, jak znaczenia związane z masowo produkowanymi i poddanymi standaryzacji towarami podlegają procesowi przetworzenia $\mathrm{w}$ toku konsumpcji. Producentowi, który wypuszcza z fabryki produkt, jakim jest nowiutka para spodni, zapewne nie przyszłoby do głowy, że można ów produkt pociąć, specjalnie zrobić w nim dziury, czy też dążyć do tego, aby jak najszybciej owa część garderoby się przetarła. 
W tradycji podkreślania oporu mieszczą się też poglądy Henry'ego Jenkinsa. Badacz ten skupia się przede wszystkim na miłośnikach Star Treka. Podobnie jak Jay Goulding snuje na tej kanwie ogólniejsze rozważania ${ }^{6}$. Inaczej jednak niż on, uważa, że fani są awangardą zaangażowaną w nowatorski sposób odbioru (Jenkins 1992a, 1992b). Wyróżniają się spośród przeciętnych odbiorców niezwykle radykalnym oporem. Na przykład odczytują teksty nie w duchu kapitalizmu czy demokracji, ale w kontekstach utopijnych ${ }^{7}$. W świecie przedstawionym danego tekstu dopatrują się postulatów związanych z ochroną praw obywatelskich rozmaitych grup społecznych.

Różne grupy fanów zatem różnie odbierają tekst, interpretują go, tak aby spełniał ich oczekiwania i odpowiadał potrzebom. Niezwykle wyraziste tego przykłady to fanki feministki (Jenkins 1988) czy fani homoseksualiści (Jenkins 2006, s. 89-112), którzy szczególną uwagę poświęcają fragmentom w najbardziej widoczny sposób odnoszącym się do ich interesów. Owych interesów bronią również przez wtórną produkcję, stawiają producentom opór przez reinterpretację oryginalnego tekstu. Dobrym przykładem mogą być spełniające oczekiwania homoseksualistów amatorskie literackie opowiadania typu slash, czyli takie, które ukazują dwóch heteroseksualnych bohaterów jako uwikłanych w homoseksualny związek (Driscoll 2006, s. 79-96; Gwenllian-Jones 2002, s. 79-90). W przypadku Star Treka najbardziej typowymi historiami slash są tak zwane K/S, czyli te łączące Kirka i jego pierwszego oficera Spocka (Nikunen 2001). Jak wskazują badania, podobne opowiadania tworzone są również przez heteroseksualnych fanów, głównie przez kobiety. Jest to również wyraz dostosowania tekstu do własnych potrzeb. Chodzi o konieczność zanegowania patriarchalnego porządku współczesnego społeczeństwa, zwrócenia uwagi na sprawy emocji i uczuć (opowiadania slash opierają się na ich eksponowaniu), a nie seksualności (Cicioni 1998, s. 153-178).

\footnotetext{
${ }^{6}$ Jenkins w znacznym stopniu inspirował się teoriami francuskiego myśliciela Michaela de Certeau, który wyróżnił z jednej strony potężne siły producenckie, medialne, popkulturowe, a z drugiej strony ciągle stawiających im opór konsumentów prowadzących działalność, którą nazwać można produkcją wtórną (Certeau 2008), i twierdził, że na polu kultury konsumpcja jest zawsze w opozycji do produkcji. Na owym polu ścierają się producencki nakaz mówiący, co i jak ma być odczytane, $z$ taktykami konsumentów interpretujących teksty po swojemu. Stąd wszelakie odczytania różnorakie, nieautoryzowane, nie wychodzące od twórców, krytyków, naukowców itd. Według de Certeau odbiorcy kultury są jak kłusownicy przemieszczający się po rozległych kniejach należących do twórców kultury, polujący na ich terenie dla własnych korzyści. Odbiorcy dopasowują odbierany tekst do siebie, są aktywni, tworzą wręcz własną kulturę $z$ elementów upolowanych i przetworzonych z oficjalnych przekazów medialnych (por. Ćwikiel 2004, s. 266-267).

7 Pokazuje to również Robert V. Kozinets $(2001,2007)$, który twierdzi, że chociaż fani Star Treka są zorientowani konsumpcjonistycznie, to aktywność swoją opierają na swoistym etosie. Ten $z$ kolei opiera się na propagowanym przez twórcę Star Treka (Gene Roddenberry) utopizmie oficjalnym celem wielu klubów jest działanie na rzecz „uczynienia świata lepszym”, eliminacji biedy i dyskryminacji, zwiększenia tolerancji — tak aby świat funkcjonował zgodnie z serialowymi ideałami.
} 
Fani zatem nie do końca odczytują teksty tak, jak chcieliby producenci. Jak widać, bardzo często traktują je jako zwiastuny zmian społecznych. Oprócz Jenkinsa twierdzą tak chociażby Camille Bacon-Smith, która zasłynęła dziełem Enterprising Women: Television Fandom and the Creation of Popular Myth (1992), czy Sara Gwenllian-Jones i Roberta Pearson, redaktorki książki Cult Television (2004), Constance Penley, która wydała NASA/Trek: Popular Science and Sex in America (1997) czy John Tulloch, autor wielu artykułów dotyczących fanów serialu Doctor Who (Tulloch, Jenkins 1995).

Warto zastanowić się, czy $\mathrm{w}$ przypadku podejścia wojennego nie należałoby złagodzić określenia "kicz” i zastosować pojęcie ukute przez Susan Sontag (1979, s. 306-323) — „kamp”. Spojrzenie to bowiem pozwala opisać sytuację, w której kiczowata (czy jak kto woli kampowa) fantastyka audiowizualna „reaguje” z gustami i smakiem fanów. Nie jest tak, że fantastyka przestaje być kiczowata, kicz jednak przestaje się liczyć jako część składowa dewiacyjnej natury fanów. Wielbiciel nie jest przecież bezkrytycznym odbiorcą, ślepo przyjmującym wszystko to, co serwuje mu producent. Ma ograniczoną „cierpliwość”. Gdy tekst stanie się zbyt kiczowaty, twórca może przekroczyć jej próg. Fan rozpoczyna wówczas „wojnę”, odrzucając część tego, co mu się proponuje, wybiera $z$ danej produkcji jedynie to, co uważa za właściwe, i przekształca ją na swój sposób. Kiczowaty tekst nie trafia zatem do manipulowanego masowego odbiorcy. Fani widzą kiczowatość, dostrzegają manipulatorskie zapędy i opierają się, gdy ich „cierpliwość” się wyczerpie.

Dokładniej można to zobrazować wspominaną już aktywnością producencką fanów. John Fiske (1992, s. 30-49) wyróżnił kilka rodzajów oddolnej działalności twórczej publiczności w ogóle: semiotyczną (semiotic), enuncjacyjną (enuntiative) oraz tekstualną (textual). Te trzy typy da się odnieść do twórczości miłośników fantastyki. Aktywność semiotyczna to po prostu tworzenie znaczeń. Fani zarówno w realu, jak i w internecie dyskutują o tym, czy kolejny serial lub film im się podoba, czy jest zgodny z tym, co uważają za kanon, czy nie jest przesiąknięty komercją, czy nie jest zbyt gadżeciarski. Fora oraz czaty internetowe aż kipią od polemik i dyskusji na temat różnorodnych tekstów (Gray 2003, s. 64-81; Gray 2005, s. 840-858; Johnson 2007, s. 285-300). Krytycyzm i jawne odrzucanie części produkcji jest powszechne. Przykładem niech będzie Star Wars - część fanów odrzuciła trzy najnowsze filmy sagi jako zbyt komercyjne. Również w wypadku Star Treka krytykowany jest najnowszy serial Enterprise czy ostatni, jedenasty film. Według wielu, nie jest on niczym innym jak tak zwanym rebootem, gdyż okazuje się całkowicie oderwany od tradycji wcześniejszych produkcji. Wielu fanów postrzega jego nakręcenie jako działanie nastawione wyłącznie na zysk. Tworzeniem własnych znaczeń są również wspominane już, opisywane przez Jenkinsa, praktyki feministek czy homoseksualistów. Jednak swoje znaczenia nie zawsze wypracowują grupy, które mają na celu ochronę praw obywatelskich. Często dotyczy to 
spraw bardziej trywialnych, związanych z odbiorem tekstu, z jego wartościami estetycznymi czy celami powstania. Tworzenie znaczeń, zarówno w wymiarze radykalnym (feministki czy homoseksualiści), jak i łagodnym, zawsze jest opieraniem się producentom, którzy chcieliby przeforsować coś, co nie odpowiada fanom.

Fani opierają się również przez aktywność enuncjacyjną, czyli interakcje ukształtowane wokół wypracowanych przez społeczność znaczeń. Dobrym przykładem są wszelkiego rodzaju akcje protestacyjne, organizowane $\mathrm{w}$ celu zapobieżenia zdjęciu serialu $\mathrm{z}$ anteny. Bardzo często odnoszą one sukces (Bortel 2005, s. 6-8). Innym przykładem może być organizowanie konwentów, czyli zlotów fanów. Opór stawia się również przez aktywność tekstualną, czyli kilka razy wspominane już tworzenie tekstów amatorskich. Bardzo często zdarza się, że fan, gdy jest niezadowolony $z$ tego, co serwuje mu producent, uważa to za zbyt kiczowate i komercyjne, chwyta ster we własne ręce. Amatorskie opowiadania literackie zmieniają fabułę odcinków bądź całych filmów. Własne produkcje filmowe przekształcają to, co widzowie znają z kin bądź telewizorów, powołują do życia to, czego nie widzieli, a co chcieliby zobaczyć. Wszelkiego rodzaju twórczość to doskonały sposób, aby wypracowane przez społeczność znaczenia urzeczywistnić (wystarczy spojrzeć na wspomnianych już fanów homoseksualistów tworzących slash).

Można zastanawiać się, czy w kontekście poglądów lansowanych przez podejście wojenne aktualności nie traci jeden $z$ wymiarów podziału na metafantastykę i parafantastykę. Jeśli fani opierają się kiczowatości i wynikającym z niej manipulatorskim zabiegom, to filmowe czy serialowe teksty, podobnie jak literatura, cechują się samorefleksyjnością. Chodzi o świadomość statusu estetycznego oraz świadomość sztuczności świata przedstawionego. Fan uświadamia sobie ów status i ową sztuczność wówczas, gdy wyczerpie się jego „cierpliwość". Wskazują na to wszystkie wymienione rodzaje aktywności: semiotyczna, enuncjacyjna i tekstualna.

W tym sensie podział na metafantastykę i parafantastykę traci znaczenie. W innych jednak wymiarach cały czas się utrzymuje — jak już zostało napisane — kicz pozostaje. Audiowizualne teksty fantastyczne bardzo często pozbawione są oryginalności - kolejne filmy czy odcinki seriali opierają się na powielanych schematach. Swą atrakcyjność zawdzięczają dostępności i czytelności treści, jak również efektom specjalnym, wizualizacjom, które mają olśnić i oczarować widzów. Tak rozumiana kiczowatość czyni z produkcji fantastycznych towar przeznaczony dla szerokiej publiczności, zapewnia jej przyjemność. Szczególne zadowolenie czerpią z tekstów fani, czyli ci, którzy są bardzo zaangażowani w odbiór. Czy jednak rzeczywiście są oni tak bardzo zaślepieni przez kicz? Czy producenci zdolni są przeforsować treści każdego rodzaju i manipulować odbiorcami niczym infantylnymi marionetkami? Zdaniem przedstawicieli podejścia wojennego - nie. 


\section{CO DALEJ Z PARTYZANTEM?}

Patrząc na dwa scharakteryzowane podejścia do fanów fantastyki, nietrudno nie zauważyć, że drugie $\mathrm{z}$ nich doskonale wpisuje się $\mathrm{w}$ dominujący dziś sposób analizowania konsumentów w ogóle. Coraz częściej postrzega się ich jako aktywnych, partycypujących i często współtworzących produkty. Mówi się chociażby o prosumentach (termin stworzony przez Alvina Tofflera), czyli odbiorcach, którzy mają szeroką wiedzę na temat produktów i usług, a co więcej - przekazują ją innym. Prosument konsumuje aktywnie, to znaczy chce mieć udział w tworzeniu — jest niezwykle wymagający, decyzje zakupowe podejmuje W wysokim stopniu świadomie. Przez to, że nie jest bierny, podejmuje dialog z producentem, staje się jego partnerem (Toffler 1986, s. 312-314; Szpunar 2009, s. 67-74; Gajewski 2009). Takie spojrzenie na konsumentów przekłada się również na specyficzne ujmowanie publiczności medialnej. Coraz częściej twierdzi się, że przemysł kulturowy zaczyna z nią współpracować - cenić zaczyna się zaangażowanie i partycypację odbiorców, gdyż mogą oni stać się siłą, która promować będzie dany produkt kultury popularnej w stopniu, w jakim nie uczyni tego żaden specjalista od marketingu (Jenkins 2006, s. 152-172; 2007b).

Jeśli przyrównamy tendencje dominujące dzisiaj w badaniach publiczności do rozważań na temat fanów fantastyki, to nietrudno dojść do wniosku, że zaczyna przeważać podejście wojenne. Czy jednak tezę tę przyjąć można bez zarzutu i absolutnie się z nią zgodzić? Wydaje się, że nie. Być może wskutek coraz powszechniejszej akceptacji przez producentów aktywnej postawy odbiorców zwolennicy spojrzenia wojennego muszą zmodyfikować swoje poglądy. Czy można bowiem dalej twierdzić, że brak „cierpliwości” ze strony fana i wynikający $z$ owego braku opór jest niezgodny $z$ interesami przemysłu kulturowego? Jeśli producenci zgadzają się, że fani są ważni, to opór nabiera innego kolorytu - wciąż jest istotny, ale ma inne znaczenie. Chęć ograniczenia kiczowatości, próba dostosowania tekstu do własnych potrzeb przestaje być działalnością wywrotową. Jeśli najmniejszy sprzeciw spotyka się z akceptacją ze strony twórcy, docenieniem, a nawet próbą „naprawienia” tego, co nie pasuje fanom, to nie ma już oporu $\mathrm{w}$ takim sensie, $\mathrm{w}$ jakim rozumieją go przedstawiciele podejścia wojennego. Skutki oporu wydają się wówczas inne niż te, które ukazują przedstawiciele paradygmatu wojennego, zakładający, że producenci rzadko są wrażliwi na sprzeciw fanów. Zasadne wydaje się wręcz pytanie o potrzebę wypracowania nowego podejścia - rewidującego sposób ujęcia oporu, funkcji, jakie spełnia, skutku, jaki odnosi. Istotne jest również pytanie o "cierpliwość" fana - wcale nie musi się ona wyczerpywać, wie on bowiem, że na jej brak ma przyzwolenie od samego początku. Fan zaczyna mieć świadomość, że producent się z nim liczy.

Wydaje się zatem, że należy dążyć do stworzenia nowego podejścia do kategorii fanów fantastyki (lub przynajmniej modyfikacji podejścia wojennego). Kto wie - być może musiałoby się ono zbliżyć do spojrzenia patologicznego, 
właśnie w związku z opisaną wyżej zmianą charakteru oporu. Zastanawiać się można, czy nie jest tak, że przemysł kulturowy znów zaczął fanami manipulować - w tym sensie, że znalazł sposób na radzenie sobie $z$ ich sprzeciwem. Odkrył, jak można czerpać z niego zyski. Najlepiej włączyć go w proces tworzenia tekstów, użyć z korzyścią dla producenta, odmienić jego oblicze w pewnym sensie zatem pozbawić go znaczenia. Jeśli fani fantastyki są „niecierpliwi”, dlaczego nie zezwolić im na większą swobodę, otworzyć się na krytykę, zaakceptować ich twórcze działania, ale jednocześnie czerpać z tego profity. Oczywiście, tego rodzaju manipulacja jest inna niż zakładali badacze z kręgu podejścia patologicznego - bardziej zakamuflowana, nie rzuca się w oczy. Ma jednak na celu podtrzymanie dominującego systemu kapitalistycznej produkcji.

Nie twierdzę kategorycznie, że nowy paradygmat należy rozwinąć $\mathrm{w}$ tym właśnie kierunku, wracając do patologizowania w stylu teoretyków konfliktu. Być może wystarczy jedynie zrewidować pogląd na temat oporu — zauważyć, że uzyskał on dziś przyzwolenie producentów oraz że dzięki temu mamy do czynienia z jeszcze większą emancypacją fanów. Ważny jest nie kierunek zmian w myśleniu, lecz samo podjęcie zagadnienia.

Jest tak $z$ jednego niezwykle ważnego powodu. Rozważania na temat fanów fantastyki są kluczowe dla rozważań o fanach w ogóle. Jak już zostało powiedziane, wielbiciele filmów i seriali fantastycznych są najbardziej istotnym segmentem zbiorowości fanów - jest ich najwięcej, są oni najbardziej widoczni. Rozstrzygnąwszy, jacy są fani fantastyki, rozstrzygniemy, jacy są fani w ogóle. Co więcej, ustalimy również, jacy są odbiorcy kultury popularnej. Jeżeli bowiem poglądy na temat fanów czerpią natchnienie $z$ teorii charakteryzujących publiczność medialną $\mathrm{w}$ ogóle, to fani są awangardą owej publiczności, są pionierami nowych trendów. Wskazuje się chociażby na to, że aktywne, partycypacyjne podejście cechowało ich na długo przedtem, zanim stało się elementem krajobrazu medialnego (Gray, Sandvoss, Harrington 2007; Jenkins 2007a). Odkrycie prawideł rządzących konsumpcją fanowską, a w szczególności konsumpcją fanów fantastyki, może zatem przyczynić się do zrozumienia odbiorców kultury popularnej w ogóle ${ }^{8}$.

${ }^{8} \mathrm{Na}$ marginesie należy zauważyć, że choć badania miłośników fantastyki rzeczywiście pozwalają wnioskować o publiczności w ogóle, to nie jest tak, że fani nie różnią się w poszczególnych częściach świata. Należy na owe różnice zwracać uwagę. Na przykład w Polsce fanizm w stylu, jaki znamy z krajów zachodnich, zaczął powstawać dopiero po transformacji ustrojowej. Polscy fani pozbawieni są zatem takiej jak na Zachodzie tradycji oporu - przed transformacją bycie fanem było dla nich sposobem na przeciwstawienie się nie przemysłowi kulturowemu, lecz komunizmowi. W związku z tym ich współczesny opór został skierowany na inne tory (na próżno na przykład będziemy szukać działalności fanów homoseksualistów czy fanek feministek). Co ciekawe, świadomość uwarunkowań antyproducenckiego działania (i poddania manipulacjom) jest wykształcona dość słabo - fani nie znają historii oraz tradycji swoich odpowiedników z krajów bardziej rozwiniętych. 


\section{BIBLIOGRAFIA}

Aldiss Brian Wilson, 1986, Trillion Year Space: The History of Science Fiction, Avon, New York.

Ali Asim, 2009, „In the World, But Not of It”: An Ethnographic Analysis of an Online „Buffy the Vampire Slayer" Fan Community, w: Mary Kirby-Diaz (red.), Buffy and Angel Conquer the Internet: Essays on Online Fandom, McFarland, Jefferson-London.

Ang Ien, 1989, Watching Dallas: Soap Opera and the Melodramatic Imagination, Routledge, London.

Bacon-Smith Camille, 1992, Enterprising Woman: Television Fandom and the Creation of Popular Myth, University of Pennsylvania Press, Philadelphia.

Bacon-Smith Camille, 2000, Science Fiction Culture, University of Pennsylvania Press, Philadelphia.

Bisko Agata, 2008, Prawie jak sztuka. O wspótczesnym kiczu wnętrzarskim, w: Wojciech J. Burszta, Elżbieta A. Sekuła (red.), Kiczosfery wspótczesności, Academica, Warszawa. Bortel Krzysztof, 2005, Medialni barbarzyńcy, „Nowa Fantastyka”, nr 9.

Brooker Will, 2002, Using the Force: Creativity, Community and Star Wars Fans, Continuum, New York-London.

Bury Rhiannon, 2005, Cyberspaces of Their Own: Female Fandoms Online, Peter Lang, New York.

Certeau Michel de, 2008, Wynaleźć codzienność: sztuki działania, tłum. Katarzyna Thiel-Jańczuk, Wydawnictwo Uniwersytetu Jagiellońskiego, Kraków.

Cicioni Marina, 1998, Male Pair-Bonds and Female Desire in Fan Slash Writing, w: Cheryl Harris, Alison Alexander (red.), Theorizing Fandom: Fans, Subculture and Identity, Hampton Press, Cresskill, NJ.

Coppa Francesca, 2006, A Brief History of Media Fandom, w: Karen Hellekson, Kristina Busse (red.), Fan Fiction and Fan Communities in the Age of the Internet, McFarland, Jefferson, NC.

Ćwikiel Agnieszka, 2004, Między narracja a serializacją: fenomen Star Trek, w: Alicja Kisielewska (red.), Między powtórzeniem a innowacją: seryjność w kulturze, Rabid, Kraków.

Driscoll Catherine, 2006, One True Pairing: The Romance of Pornography and the Pornography of Romance, w: Karen Hellekson, Kristina Busse (red.), Fan Fiction and Fan Communities in the Age of the Internet, McFarland, Jefferson, NC.

Ebert Teresa, 1980, The Convergence of Postmodern Innovative Fiction and Science Fiction, „Poetics Today”, t. 1, s. 91-104.

Fiske John, 1992, The Cultural Economy of Fandom, w: Lisa A. Lewis (red.), The Adoring Audience: Fan Culture and Popular Media, Routledge, London-New York.

Fiske John, 2003, Reading the Popular, Routledge, New York.

Fiske John, 2005, Understanding Popular Culture, Routledge, New York.

Gajewski Łukasz, 2009, Prosumpcja — praktyki konsumenckiej innowacyjności, „e-mentor”, nr 2.

Godzic Wiesław, 2001, Rozumieć telewizję, Rabid, Kraków.

Goulding Jay, 1985, Empire, Aliens and Conquest, Sisyphus, Toronto.

Gray Jonathan, 2003, New Audiences, New Textualities: Anti-Fans and Non-Fans, „International Journal of Cultural Studies", t. 6, s. 64-81.

Gray Jonathan, 2005, Antifandom and the Moral Text: Television Withoout Pity and Textual Dislike, „American Behavioral Scientist”, t. 48, s. 801-821. 
Gray Jonathan, Sandvoss Cornel, Harrington C. Lee, 2007, Introduction: Why Study Fans?, w: Jonathan Gray, Cornel Sandvoss, Lee C. Harrington (red.), Fandom: Identities and Communities in a Mediated World, New York University Press, New York-London.

Gwenllian-Jones Sara, 2002, The Sex Lives of Cult Television Characters, „Screen”, t. 43, s. 79-90.

Gwenllian-Jones Sara, Pearson Roberta E. (red.), 2004, Cult Television, University of Minnesota Press, Minneapolis-London.

Hebdige Dick, 1988, Hiding in the Light: On Images and Things, Routledge, London.

Hinerman Stephen, 1992, „I'll Be Here With You”: Fans, Fantasy and the Figure of Elvis, w: Lisa A. Lewis (red.), The Adoring Audience: Fan Culture and Popular Media, Routledge, London-New York.

Hoggart Richard, 1976, Spojrzenie na kulturę robotnicza w Anglii, tłum. Aleksandra Ambros, Państwowy Instytut Wydawniczy, Warszawa.

Jenkins Henry, 1988, Star Trek Rerun, Reread, Rewritten: Fan Writing as Textual Poaching, „Critical Studies in Mass Communications”, t. 5, s. 85-107.

Jenkins Henry, 1992a, „Strangers No More, We Sing”: Filking and the Social Construction of the Science Fiction Community, w: Lisa A. Lewis (red.), Adoring Audience: Fan Culture and Popular Media, Routledge, London-New York.

Jenkins Henry, 1992b, Textual Poachers: Television Fans and Participatory Culture, Routledge, New York.

Jenkins Henry, 2006, Fans, Bloggers, and Gamers, New York University Press, New York.

Jenkins Henry, 2007a, Afterword: The Future of Fandom, w: Jonathan Gray, Cornel Sandvoss, Lee C. Harrington (red.), Fandom: Identities and Communities in a Mediated World, New York University Press, New York-London.

Jenkins Henry, 2007b, Kultura konwergencji: zderzenie starych i nowych mediów, tłum. Małgorzata Bernatowicz, Mirosław Filiciak, Wydawnictwa Akademickie i Profesjonalne, Warszawa.

Jenson Joli, 1992, Fandom as Pathology: The Consequences of Characterization, w: Lisa A. Lewis (red.), The Adoring Audience: Fan Culture and Popular Media, Routledge, London-New York.

Johnson Derek, 2007, Fan-tagonism: Factions, Institutions, and Constitutive Hegemonies of Fandom, w: Jonathan Gray, Cornel Sandvoss, Lee C. Harrington (red.), Fandom: Identities and Communities in a Mediated World, New York University Press, New York-London.

Kirby-Diaz Mary, 2009, Buffy, Angel, and the Creation of Virtual Communities, w: Mary Kirby-Diaz (red.), Buffy and Angel Conquer the Internet: Essays on Online Fandom, McFarland, Jefferson-London.

Kitabayashi Ken, 2004, The „Otaku” Group from a Business Perspective: Revaluation of Enthusiastic Consumers, „Nomura Research Institute Papers”, nr 84.

Kozinets Robert V., 2001, Utopian Enterprise: Articulating the Meanings of Star Trek's Culture of Consumption, „Journal of Consumer Research”, t. 28, s. 67-89.

Kozinets Robert V., 2007, Inno-tribes: Star Trek as Wikimedia, w: Bernard Cova, Robert V. Kozinets, Avi Shankar (red.), Consumer Tribes, Elsevier, London-New York.

Macdonald Dwight, 2002, Kultura masowa, tłum. Czesław Miłosz, Wydawnictwo Literackie, Warszawa.

Marcuse Herbert, 1991, Człowiek jednowymiarowy, tłum. Stanisław Konopacki, Państwowe Wydawnictwo Naukowe, Warszawa. 
Mellor Adrian, 1984, SF and the Crisis of the Educated Middle Class, w: Christopher Pawling (red.), Popular Fiction and Social Change, Macmillan, London.

Moles Abraham, 1978, Kicz, czyli sztuka szczęścia. Studium z psychologii kiczu, tlum. Anita Szczepańska, Ewa Wende, Państwowy Instytut Wydawniczy, Warszawa.

Mittell Jason, 2009, Sites of Participation: Wiki Fandom and the Case of Lostpedia, „Transformative Works and Cultures", t. 3, http://journal.transformativeworks.org/index. $\mathrm{php/twc/article/view/118/117} \mathrm{[25.05.2010].}$

Nikunen Kaarina, 2001, Dangerous Emotions? Finnish Television Fans and Sensibilities of Fandom, w: Anu Koivunen, Susanna Paasonen (red.), Conference Proceedings for Affective Encounters: Rethinking Embodiment in Feminist Media Studies, University of Turku, School of Art, Literature and Music; http://media.utu.fi/affective/nikunen.pdf [25.05.2010].

Penley Constance, 1997, Nasa/Trek: Popular Science and Sex in America, Verso, London-New York.

Pugh Sheenagh, 2005, The Democratic Genre: Fan Fiction in a Literary Context, Seren, Glasgow.

Rey Lester del, 1979, The World of Science Fiction: The History of a Subculture, 1926-1976, Ballantine, New York.

Sandvoss Cornel, 2005, Fans: The Mirror of Consumption, Polity Press, Cambridge.

Sharratt Bernard, 1980, The Politics of the Popular? From Melodrama to Television, w: David Bradby, Louis James, Bernard Sharratt (red.), Performance and Politics in Popular Drama, Cambridge University Press, Cambridge.

Siuda Piotr, 2008a, Polski antyfan. Patrzac na fanizm, nie zapomnijmy o antyfanizmie, „Kultura Popularna", nr 3.

Siuda Piotr, 2008b, Wptyw Internetu na rozwój fandomów, czyli o tym, jak elektroniczna sieć rozwija i popularyzuje społeczności fanów, w: Marek Sokołowski (red.), Media i społeczeństwo. Nowe strategie komunikacyjne, Wydawnictwo Adam Marszałek, Toruń.

Siuda Piotr, 2010, Od dewiacji do głównego nurtu — ewolucja akademickiego spojrzenia na fanów, „Studia Medioznawcze” 2010, nr 3.

Sontag Susan, 1979, Notatki o kampie, „Literatura na Świecie”, nr 9.

Stein Louisa Ellen, 2010, „What You Don't Know”: Supernatural Fan Vids and Millennial Theology, „Transformative Works and Cultures”, nr 4; http://journal.transformativeworks.org/index.php/twc/article/view/192/158 [25.05.2010].

Storey John, 2003, Studia kulturowe $i$ badania kultury popularnej, tłum. Janusz Barański, Wydawnictwo Uniwersytetu Jagiellońskiego, Kraków.

Strinati Dominic, 2005, Wprowadzenie do kultury popularnej, tłum. Wojciech J. Burszta, Zysk i S-ka, Poznań.

Szkudlarek Artur, 2001, Cultural Studies - brytyjska teoria krytyczna, w: Bogusława Dobek-Ostrowska (red.), Nauka o komunikowaniu. Podstawowe orientacje teoretyczne, Wydawnictwo Uniwersytetu Wrocławskiego, Wrocław.

Szpunar Magdalena, 2009, Wspótczesny konsument - pasywny, czy aktywny prosument?, w: Zbigniew Zieliński, Rola informatyki $w$ naukach ekonomicznych $i$ spotecznych: innowacje $i$ implikacje interdyscyplinarne, Wydawnictwo WSH, Kielce.

Toffler Alvin, 1986, Trzecia fala, tłum. Ewa Woydyłło, Państwowy Instytut Wydawniczy, Warszawa.

Tulloch John, Jenkins Henry, 1995, Science Fiction Audiences: Watching „Doctor Who” and „Star Trek”, Routledge, London-New York. 
Verba Joan Marie, 2003, Boldly Writing: A Trekker Fan and Zine History, 1967-1987, FTL Publications, Minnetonka, MN.

THE PATIENCE OF THE FAN OF SCIENCE FICTION, ON WHETHER THE FAN IS A PUPPET OR GUERILLA

\section{Summary}

The article discusses a specific group of the recipients of the media - fans of science-fiction. The author describes two research approaches to sci-fi fans - a pathological approach and a warlike approach. The pathological one shows fans as infantile puppets. According to the representatives of this approach the science-fiction genre is kitsch. Fans are completely tasteless, dumb and easily yield to manipulation by the producers. The second approach opposes this notion. According to the representatives of the warlike approach, fans are quite impatient when it comes to kitsch. Fans often reject a part of a text producers present. Fans are selective - they choose what they think is good and valuable. One could say that the fans are fighting with producers, that they are a guerillas involved in a war. Fans try to pick something up out of a text and create a new fan culture. The author of the article characterizes both approaches, indicates their main assumptions and recognized representatives. It is possible to accept the thesis that a fan is a warlike guerrilla without any reservations? If a cultural industry is currently changing to accommodate the most engaged and participatory audiences, researchers should come up with a new approach. It could portray sci-fi fans rather as engaged in war with producers (but recapitulate ideas of fannish opposition) or once again manipulated. In the near future it is important to decide which way the new approach should take - researching fans of science fiction genre is crucial to understanding audiences in general.

\section{Key words/słowa kluczowe}

fans / fani; fandom / fandom; audio-visual science-fiction / fantastyka audiowizualna; fan studies / badania fanów; kitsch / kicz; camp / kamp 